\title{
MULTIPLE PROCESS PARAMETER OPTIMIZATION OF FORWARD EXTRUSION PROCESS ON AA 2024
}

\author{
Anupama Francy Kothasiri ${ }^{1}$, Srinivasa Rao Chalamalasetti ${ }^{2}$, Gopalakrishnaiah Peteti $^{3}$ \\ ${ }^{1}$ Vishnu Institute of Technology, Bhimavaram, West Godavari, Andhra Pradesh, India, Pin code 534202 \\ ${ }^{2}$ Andhra University College of Engineering, Visakhapatnam, Andhra Pradesh, India. Pin code 530003 \\ ${ }^{3}$ PVP Siddhartha Institute of Technology, Vijayawada, Andhra Pradesh, India. Pin code 520007 \\ Corresponding author: Anupama Francy Kothasiri, kothasirianupama@gmail.com
}

\begin{abstract}
Extrusion is a simple metal forming process in which a block of metal is forced through a die orifice with a certain shape under high pressure. This extrusion process is influenced by many process parameters such as die angle (DA), ram speed (RS), coefficient of friction (COF), Extrusion ratio, Die land height, work piece diameter and length, material properties etc. In extrusion process, extrusion force is crucial parameter, the flow of metal and hence the extrusion force is significantly influenced by the above parameters which results in quality of the product. The present study numerically investigates the influence of major process parameters such as die angle, ram speed, coefficient of friction on the extrusion process. The AA2024 material is chosen as work piece material and the extrusion force and damage is considered as the output responses. The input process parameters are varied in three levels (Level - 1: $10^{\circ} \mathrm{DA}, 1.6 \mathrm{~mm} / \mathrm{min} \mathrm{RS}, 0.06 \mathrm{COF}$; Level - 2: $20^{\circ} \mathrm{DA}, 3.2 \mathrm{~mm} / \mathrm{min} \mathrm{RS}, 0.08 \mathrm{COF}$; Level - 3: $\left.30^{\circ} \mathrm{DA}, \quad 4.8 \mathrm{~mm} / \mathrm{min} \mathrm{RS}, \quad 0.01 \mathrm{COF}\right)$. Numerical simulations are performed by using DEFORM 3D software. The simulations are conducted as per $\mathrm{L}_{27}$ orthogonal array. From the results it is observed that Increase of die angle, ram speed and coefficient of friction increases the extrusion force. The die angle has highest $(86.45 \%)$ influence on the extrusion force, then after ram speed $(6.60 \%)$. The coefficient of friction has insignificant influence $(0.55 \%)$. It is also noticed that the damage is considerable after the $20^{\circ}$ die angle. A multi parameter optimization is also done by using the Grey relation analysis by considering the equal weightage of extrusion force and damage. The optimum levels of input process parameters for the minimum extrusion force and damage is DA level 1, RS level 1, and COF level 3.
\end{abstract}

Key words: Aluminium 2024, Extrusion, Grey relational analysis, Die angle, Ram speed and Coefficient of Friction, ANOVA

\section{INTRODUCTION}

The automobile and aerospace industry needs the high precision components for proper alignment in the assembly operations. In general, these components are prepared by various metal forming processes like extrusion (hot and cold), drawing, rolling, forging and stretch forming. Some of the processes are having their own operational constraints. For example, deep drawing used only for cup shaped products. Most of the components are bars and pipes of different cross sectional area. These bars and pipes are prepared by either in extrusion or drawing process. However, the extrusion process (passing bulk material through a die with a certain shape under high pressure) is widely used due to ease of operation. The extrusion process is of two types' cold extrusion and hot extrusion. The cold extrusion has an added advantage of improved mechanical properties than hot extrusion process.

The extrusion process seems to be simple but there is a number of parameters such as cross-sectional area, half die angle, ram speed, frictional conditions, extrusion ratio and material properties of the work piece influence the extrusion process (1). Several experimental and numerical studies are available in the open literature to understand the effect of the above parameters during the extrusion process. Effective die entrance angles are analysed through experiments for materials like Aluminium, Lead, Steel etc. to calculate minimum extrusion force (2-6). The extrusion force was increased till reaches a maximum die angle of $80^{\circ}$ and then drops suddenly to zero at $110^{\circ}$, because of the extreme distortion that happens at larger die angles.

Coefficient of friction also plays a vital role in reducing the extrusion power in cold and hot extrusion method. A simple numerical approach is developed based on the lubrication approximation for obtaining the optimal die design. Taguchi $\mathrm{L}_{9}$ orthogonal array is designed for the set of extrusion variables to simulate the experimental results with finite element analysis $(7,8)$. Ram speed is also considered as an input parameter along with other parameters in the extrusion process to minimize 
extrusion force. Extrusion power increased through the growing speed of punch since the greater punch speed origins complex strain rate besides larger flow stress. The impact of ram speed shows maximum effects on the extrusion force, hence ram speed was also considered as a significant parameter (9-12).

Nowadays, on improvement in the manufacturing growth simulation capability allows the designer to use computer aided design, which results in more accuracy, reduces design time, improves tolerance at each stage of the process (13-16). A basic numerical method for obtaining the optimal die configuration is developed based on the lubrication approximation. Taguchi $\mathrm{L}_{9}$ orthogonal array is designed to replicate the experimental outcome with the collection of extrusion variables. The results revealed that die position, punch speed and friction values remain the most significant constraints. Several researchers attempted on optimization of process parameters associated with extrusion process so far. Most of the authors are mainly focussing mainly on minimisation extrusion force.

Venketesan et al (17) numerically studied the influence of die angle and extrusion ratio on extrusion force. The authors further optimized these parameters to obtain the minimum extrusion force. Similarly, Sadollah et al (12) numerically optimize the extrusion force by using the simulated annealing technique. Venkatesan and Narayanasamy (18) proposed a genetic algorithm to optimize the extrusion force by considering extrusion die ratio and die cone angle as influence parameters. Tapas et.al $(13,14)$, conducted extrusion simulations for the material Aluminium 6061 alloy at the reduction ratios of $20: 1$ and 60:1 through round and square dies. Thella Babu rao et.al (19) numerically analysed the optimum process parameters (die angle, ram speed coefficient of friction) for extrusion process of the Aluminium 6061 alloy. The authors suggest an integrated FEA based approach to find the best process variables for the forward extrusion process. Optimization is done with the help of Taguchi method to minimize the extrusion load and temperature.

Farhoumand and Ebrahimi (20) numerically investigate the effect of geometrical parameters such as die corner radius and gap height as well as process condition such as friction between the work pieces and die for the forward extrusion. ABAQUS software was used for finite element simulations. The numerical method is validated with the help of experimental data in terms of form loadings, material flow, strain and hardness distribution in longitudinal cross-section of the product. The relation between hardness and strain value is compatible with the earlier work of the authors.

From the literature, it is observed that, the major process parameters such as die angle (DA), ram speed
(RS), and coefficient of friction (COF) significantly influences the extrusion output parameters. So, in the present work numerically analyse the influence of these parameters on extrusion process. The output extrusion process parameters considered in this study is extrusion force, damage factor. Multiple output parameter optimizations are also done by using the Grey Relation analysis by considering the equal weightage of extrusion force and damage factor.

\section{MATERIALS AND METHODS}

Figure 1 depicts the work flow chart followed in the present work and can be categorized mainly of three major steps. In the first step, work piece material selection and extrusion process influencing parameters are chosen. Initially the ranges of input process parameters are chosen then after levels are determined. In the second step, the simulation matrix is prepared based on the Taguchi method and simulation is done by using DEFORM 3D software. In the final step, based on the outcomes from the simulation. The influence of input process parameters is analysed. Optimization is done by using Taguchi and Grey relation algorithm. The subsequent section completely describes every step in detail.

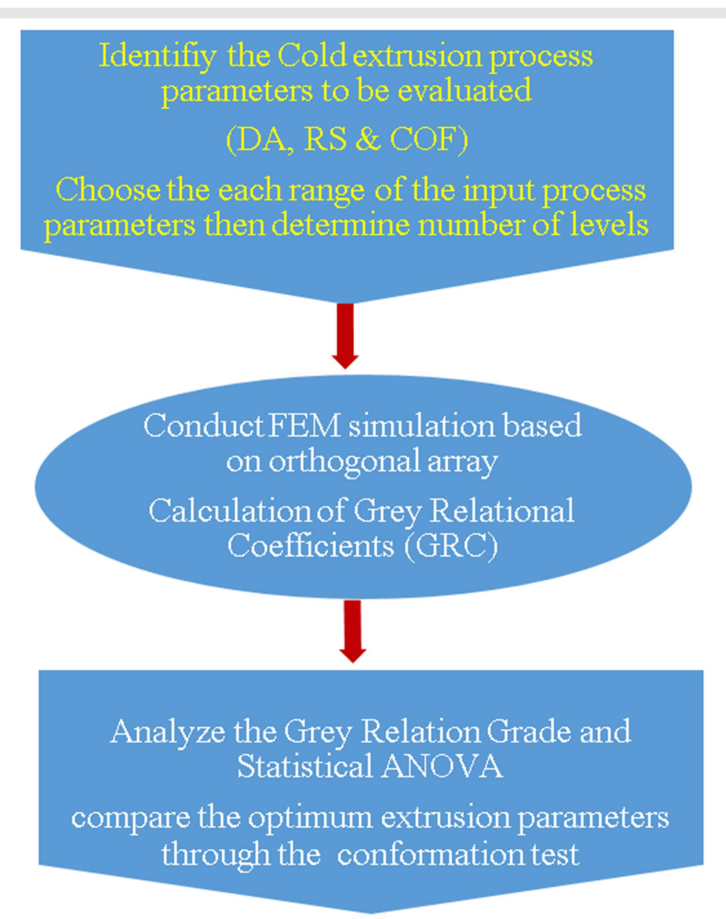

Fig. 1. Research Workflow map

\subsection{Selection of extrusion material and influence parameters}

Work piece material used for the present simulation is Aluminium alloy AA2024. AA2024 is an economical material, having good physical properties (density 2.78 $\mathrm{g} / \mathrm{cm}^{3}$, Young's Modulus is $73.1 \mathrm{GPA}$, tensile yield strength is $324 \mathrm{MPa}$ and Poisson's ratio is 0.33 ), and 
have a high surface finish and corrosion resistance [24]. Hence, AA2024 material is widely used in applications like navy ship-building, aircraft structures especially wing and fuselage structures, commercial \& military aircraft etc. The detailed composition of the AA2024 material is presented in Table 1. The die and ram are made up of $\mathrm{H} 13$ steel. The H13 steel chemical composition and physical properties are presented in Table 2. The material H13 steel is used because of its high resistance to fatigue cracking.

The final extruded product's quality depends upon the parameters which influence the extrusion process. In general, the major parameters influencing the extrusion process is ram speed, die angle, billet diameter and length, coefficient of friction and extrusion ratio, material flow, die land height. However, optimization done by considering all these parameters leads to more complications. So, in the present work, basic parameters like Die Angle, Coefficient of Friction and Ram Speed are chosen in the present study.

\subsection{Simulation matrix}

Taguchi and Konishi (21) developed a method to do the optimization of multiple variables of multiple objectives. In this method, major influencing parameters play a vital role, which has been used to achieve optimum levels of process parameters for the generation of quality characteristics. It employs an orthogonal array (OA) that has been used to learn the complete process parameters spacing with the least simulation possible. The levels of input factors selected for this study are listed in Table 3. In Taguchi optimization, $\mathrm{S} / \mathrm{N}$ ratio stands the measure of quality characteristics and is estimated as follows.

For smaller is better

$$
\frac{\mathrm{s}}{\mathrm{N}}=\eta=-10 \log _{10}\left[\frac{1}{\mathrm{n}} \sum_{\mathrm{i}=1}^{\mathrm{n}} \mathrm{y}_{\mathrm{i}}^{2}\right]
$$

For larger is better

$$
\frac{S}{N}=\eta=-10 \log _{10}\left[\frac{1}{n} \sum_{i=1}^{n} \frac{1}{y_{i}^{2}}\right]
$$

In the present work, $\mathrm{S} / \mathrm{N}$ ratio is determined for extrusion force and damage factor and smaller-is-thebetter criterion used to minimize both the extrusion force and damage factor. Table 3 provides the different levels of influencing parameters for the extrusion process and Table 4 shows the details of orthogonal array (OA) simulation matrix with the output response data.

Table 1. Element Composition of AA 2024 work piece [23]

\begin{tabular}{|l|l|l|l|l|l|l|l|l|l|}
\hline Element & Fe & $\mathbf{C u}$ & $\mathbf{Z n}$ & $\mathbf{S i}$ & $\mathbf{C r}$ & $\mathbf{M g}$ & $\mathbf{M n}$ & $\mathbf{T i}$ & $\mathbf{A l}$ \\
\hline Composition (wt. \%) & 0.19 & 4.66 & 0.02 & 0.08 & 0.1 & 1.35 & 0.69 & 0.01 & $\mathrm{Bal}$ \\
\hline
\end{tabular}

\begin{tabular}{|c|c|c|c|c|c|c|c|c|c|c|}
\hline \multicolumn{11}{|c|}{ Chemical Composition } \\
\hline Element & $\mathrm{Cr}$ & $\mathrm{Mn}$ & Mo & $\mathrm{V}$ & $\mathrm{C}$ & $\mathrm{Ni}$ & $\mathrm{P}$ & $\mathrm{Cu}$ & $\mathrm{S}$ & $\mathrm{Si}$ \\
\hline Composition $(\%)$ & 5.25 & 0.40 & 1.35 & 1.00 & 0.40 & 0.3 & 0.03 & 0.25 & 0.03 & 1.00 \\
\hline \multicolumn{11}{|c|}{ Physical properties } \\
\hline Density & \multicolumn{3}{|c|}{ Melting point } & \multicolumn{4}{|c|}{ Modulus of elasticity } & \multicolumn{3}{|c|}{ Poisson's ratio } \\
\hline $7.80 \mathrm{~g} / \mathrm{cm}^{3}$ & \multicolumn{2}{|c|}{$1427^{\circ} \mathrm{C}$} & & \multicolumn{4}{|c|}{$215 \mathrm{GPa}$} & \multicolumn{3}{|c|}{$0.27-0.30$} \\
\hline
\end{tabular}

Table 2. Element Composition of H13steel used for die [24]

Table 3. Input Factors and their levels

\begin{tabular}{|l|c|c|c|c|}
\hline \multicolumn{1}{|c|}{ Factors } & Representation & Level 1 & Level 2 & Level 3 \\
\hline Die Angle (deg) & DA & 10 & 20 & 30 \\
\hline Ram Speed (mm/min) & RS & 1.6 & 3.2 & 4.8 \\
\hline Coefficient of Friction & COF & 0.06 & 0.08 & 0.1 \\
\hline
\end{tabular}

Table 4. Design of $\mathrm{L}_{27}$ orthogonal array and the simulation results

\begin{tabular}{|c|c|c|c|c|c|}
\hline Exp. No & $\begin{array}{c}\text { Die } \\
\text { Angle }\end{array}$ & $\begin{array}{c}\text { Ram } \\
\text { Speed }\end{array}$ & $\begin{array}{c}\text { Coefficient } \\
\text { of Friction }\end{array}$ & Extrusion Force (KN) & Damage (\%) \\
\hline 1 & 1 & 1 & 1 & 136.56 & 0.017 \\
\hline 2 & 1 & 1 & 2 & 139.66 & 0.014 \\
\hline 3 & 1 & 1 & 3 & 142.61 & 0.011 \\
\hline 4 & 1 & 2 & 1 & 159.01 & 0.192 \\
\hline 5 & 1 & 2 & 2 & 160.01 & 0.24 \\
\hline 6 & 1 & 2 & 3 & 161.1 & 0.21 \\
\hline 7 & 1 & 3 & 1 & 179.28 & 0.159 \\
\hline 8 & 1 & 3 & 2 & 180.32 & 0.161 \\
\hline 9 & 1 & 3 & 3 & 182.31 & 0.151 \\
\hline 10 & 2 & 1 & 1 & 180.69 & 0.476 \\
\hline
\end{tabular}




\begin{tabular}{|c|c|c|c|c|c|}
11 & 2 & 1 & 2 & 186.72 & 0.472 \\
\hline 12 & 2 & 1 & 3 & 190.61 & 0.418 \\
\hline 13 & 2 & 2 & 1 & 187.51 & 0.015 \\
\hline 14 & 2 & 2 & 2 & 192.79 & 0.367 \\
\hline 15 & 2 & 2 & 3 & 196.61 & 0.41 \\
\hline 16 & 2 & 3 & 1 & 224.1 & 0.014 \\
\hline 17 & 2 & 3 & 2 & 236.01 & 0.35 \\
\hline 18 & 2 & 3 & 3 & 260.01 & 0.31 \\
\hline 19 & 3 & 1 & 1 & 286.01 & 0.82 \\
\hline 20 & 3 & 1 & 2 & 298.38 & 0.862 \\
\hline 21 & 3 & 1 & 3 & 313.89 & 0.83 \\
\hline 22 & 3 & 2 & 1 & 319.46 & 2.23 \\
\hline 23 & 3 & 2 & 2 & 316.55 & 1.93 \\
\hline 24 & 3 & 2 & 3 & 317.12 & 1.86 \\
\hline 25 & 3 & 3 & 1 & 323.01 & 2.8 \\
\hline 26 & 3 & 3 & 2 & 336.06 & 2.78 \\
\hline 27 & 3 & 3 & 3 & 345.08 & 2.62 \\
\hline
\end{tabular}

\subsection{DEFORM 3D Simulation procedure}

The present simulations are carried out in DEFORM3D V6.1 software by using FEM. The DEFORM-3D system consists of three major modules: preprocessor, processor and post-processor. Initially die, work piece and punch tool is modelled in CATIA software (Figure 2). The geometrical details of die, work piece and punch tool are depicted in table 5. In the pre-processor module, cold extrusion setup is done (Figure 3(a)). The post processor of extrusion process is as shown in Figure 3 (b \& c). Meshing is done only for the billet with 140000 tetrahedral elements. The top die (ram) and bottom die considered as rigid materials. Coefficient of friction and ram movement direction is selected as boundary conditions for the cold extrusion. In the second module to do simulations, the Newton-Raphson method is used for the solution of the non-linear simulation equations. After the converging of each simulation, the extrusion force and damage data are noted for optimization purpose.

Figure 3 (b \& c) depicts the effective stress distributions along with the load-time curve for the billet having $20^{\circ}$ die angle. The extrusion process occurs with ram speed of $3.2 \mathrm{~mm} / \mathrm{min}$ and 0.08 coefficient of friction considered at the interface of die \& work piece. It is observed that as ram pushes the material, the extrusion force is increases reaches a yield value that means the plastic deformation begins this can be observed in Figure 3(b) load time curve. Further the material start to flow from the die. The material undergoes compression and the maximum stress developed at the cross section changes (Figure $3(\mathrm{c}))$.

\subsection{Grey Relation Method of Multi Objective Optimization}

Grey relational method extensively used in multiple objective optimization problems (22). This method resolves complications in the inter relationship among multi variable optimization. The detailed procedure of the GRA optimization is discussed here. The foremost step is evaluation of $\mathrm{S} / \mathrm{N}$ ratio from the simulation data starting from 0 to 1 by using equation 1. Then after Grey relation Normalization, Grey relational coefficient (GRC) and resolve of Grey relational grade (GRG) are to be evaluated. The standardized data of the extrusion force and damage factor from the simulation is used to estimate the grey relational normalization for the lower-the-better condition and is given in equation 3.

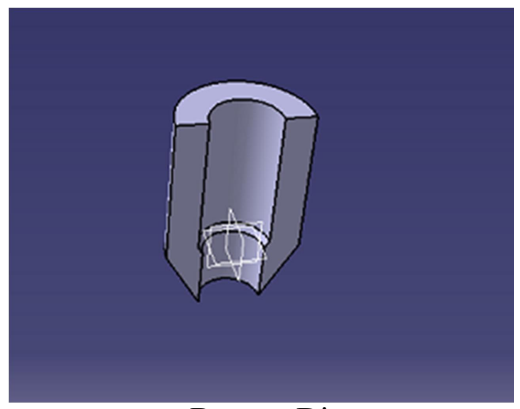

Bottom Die

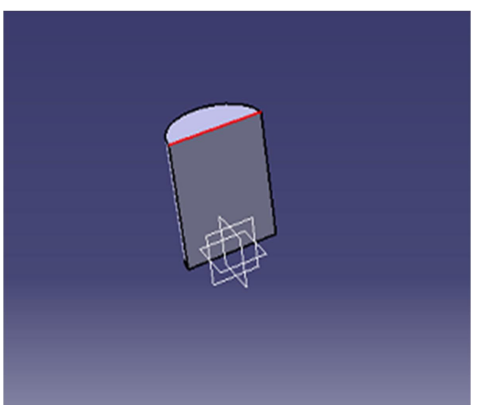

Work piece

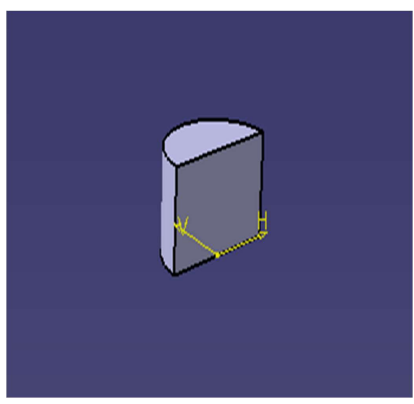

Top Die(ram)

Fig. 2. Initial models of die, work piece and punch tool 


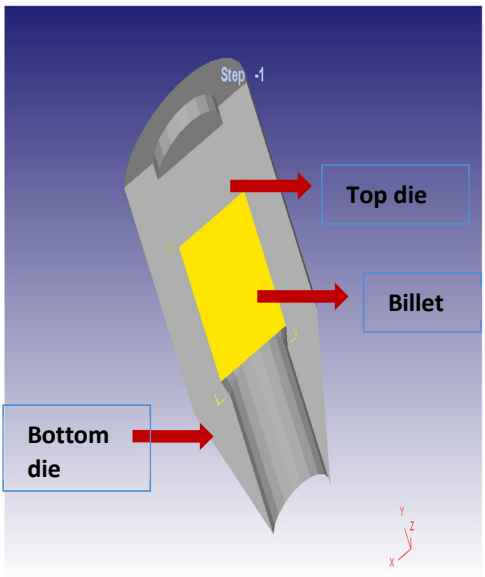

(a) work piece at initial position

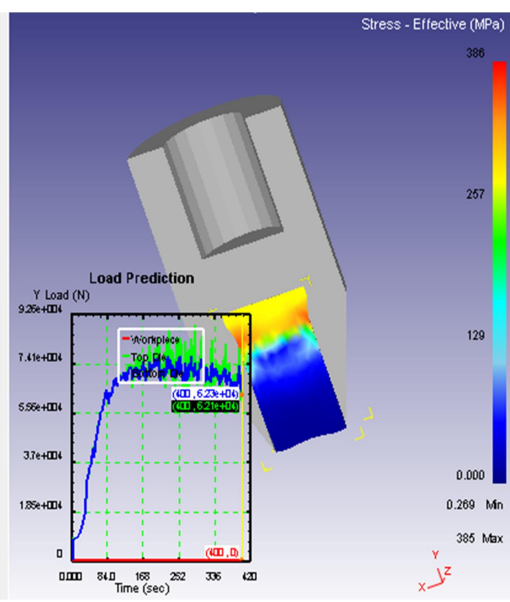

(b) Simulation run at 350

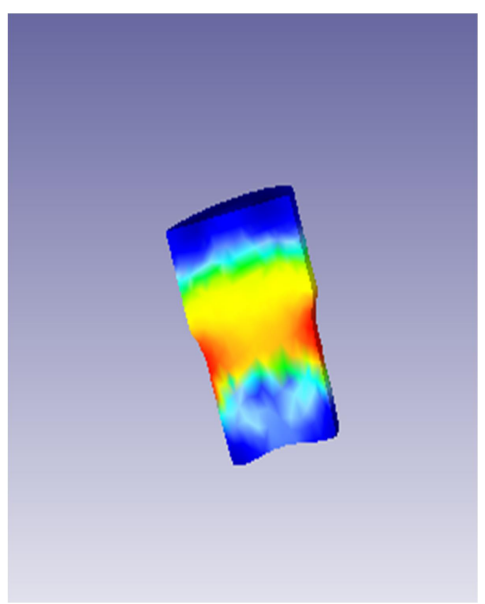

(c) work piece after extrusion

Fig. 3. (a) work piece and die at its initial position (b) load\& displacement (c) work piece after extrusion

Table 5. Geometrical details of die, work piece and ram

\begin{tabular}{|l|l|}
\hline Parameter & Dimension \\
\hline Work piece diameter & $32 \mathrm{~mm}$ \\
\hline Work piece length & $40 \mathrm{~mm}$ \\
\hline Top die height & $20 \mathrm{~mm}$ \\
\hline Top die diameter & $32 \mathrm{~mm}$ \\
\hline Inside diameter of the bottom die & $32.2 \mathrm{~mm}$ \\
\hline Outside diameter of the bottom die & $50 \mathrm{~mm}$ \\
\hline Die angles & $10^{\circ}, 20^{\circ} \& 30^{\circ}$ \\
\hline
\end{tabular}

$$
x_{i}(k)=\frac{\max y_{\mathrm{i}}(\mathrm{k})-\mathrm{y}_{\mathrm{i}}(\mathrm{k})}{\left(\max \mathrm{y}_{\mathrm{i}}(\mathrm{k})-\min \mathrm{y}_{\mathrm{i}}(\mathrm{k})\right)}
$$

where $\mathrm{x}_{\mathrm{i}}(\mathrm{k})$ is the value after Grey relational generation, min $y_{i}(k)$ is the smallest value of $y_{i}(k)$ for the $\mathrm{k}^{\text {th }}$ response, and max $\mathrm{y}_{\mathrm{i}}(\mathrm{k})$ is the largest value of $\mathrm{y}_{\mathrm{i}}(\mathrm{k})$ for the $\mathrm{k}^{\text {th }}$ response.

After normalizing the new order, the resulting step is to find out the Grey relational coefficient $\varepsilon_{i}(k)$

$$
\varepsilon_{i}(k)=\frac{\Delta_{\min }+\varphi \Delta_{\max }}{\Delta_{\mathrm{oi}}(\mathrm{k})+\varphi \Delta_{\max }}
$$

where $\Delta_{o i}=\left\|\mathrm{x}_{\mathrm{o}}(\mathrm{k})-\mathrm{x}_{\mathrm{i}}(\mathrm{k})\right\|=$ change of entire value $\mathrm{x}_{0}(\mathrm{k})$ and $\mathrm{x}_{\mathrm{i}}(\mathrm{k}) ; \Delta_{\max }$ exhibit the value for maximum of $\Delta_{o i}, \Delta_{\min }$ exhibits for minimum of $\Delta_{o i}$ and $\varphi$ is individual coefficient. Grey relational is the average response of each grey relational coefficient. Grey relational grade $\gamma_{\mathrm{i}}$ can be estimated by equation 5 and is given below

$$
\gamma_{i}=\frac{1}{n} \sum_{k=1}^{n} \varepsilon_{i}(k)
$$

$n$ stands for the number of process response.

\section{RESULT AND DISCUSSION}

The influence of process parameters (die angle, ram speed and coefficient of friction) on extrusion force and damage factor is numerically analysed. As explained earlier a total of 27 simulations are designed by using Taguchi $\mathrm{L}_{27}$ orthogonal array method. Simulations are performed in DEFORM-3D software and the obtained results are used to optimize the extrusion process parameters.

\subsection{Effect of process parameters on Extrusion Force}

The influence of process parameters (die angle, ram speed and coefficient of friction) on minimum extrusion force is depicted in Figure 4 and the results are tabulated in Table 6. From Figure 4 it is observed that increase of die angle, ram speed and coefficient of friction increases the extrusion force, the increase in die angle increases the material flow within the die due to the increase of contact area. Hence, more force required to execute the extrusion process. If the ram speed increases, the billet temperature increases which results in more force required to extrude the material from the die. The influence of coefficient of friction is insignificant on extrusion force. From the ANOVA results it is observed that die angle (DA) has highest significance $(86.45 \%)$ followed by ram speed (RS) $(6.95 \%)$. Whereas the coefficient of friction (COF) $(0.55 \%)$ has insignificant influence and same is depicted in Figure 4(b). The products of process parameters $\mathrm{DA}^{2}$ has significant influence and for $\mathrm{RS}^{2}$ have a less significant influence on extrusion force. The other parameters $\left(\mathrm{COF}^{2}\right.$, $\mathrm{DA} \times \mathrm{COF}, \mathrm{DA} \times \mathrm{RS} \& \mathrm{RS} \times \mathrm{COF}$ ) influence on extrusion force is insignificant (Table 6). The combined influence of die angle, ram speed and coefficient of friction are easily analyses from the contour plots. Figure 5 (a, b and c) depicts the contour plots of extrusion by keeping the one parameter as constant and the other two parameters varying. It clearly observed from Figure 5 $(\mathrm{a}, \mathrm{b} \& \mathrm{c})$ the coefficient of friction influence with addition to either one of the process parameter (ram speed/die angle) on extrusion force is insignificant. The maximum of $0.08 \%$ variations in extrusion force is noticed as coefficient of friction varies from 0.06 to 0.1 . Whereas, the combined influence of die angle and ram speed parameters have a strong influence. From Figure 5 , it observed that as die angle and ram speed decreases the minimum extrusion force is obtained. Therefore the optimized process parameters for minimum extrusion 
force are $10^{\circ}$ die angle, $1.6 \mathrm{~mm} / \mathrm{min}$ ram speed and 0.1 coefficient of friction.

The relationship between extrusion process parameters on extrusion force is modelled by a polynomial equation with the second order. The regression equations are obtained together with determination coefficients ( $\mathrm{R}^{2}$ adjacent- $98.32 \%$ and $\mathrm{R}^{2}$ predicted $\left.-97.28 \%\right)$. The extrusion force model $(98.9 \%)$ is given by equation (6).

Force $(\mathrm{N})=173.1-6.10 \mathrm{DA}-5.0 \mathrm{RS}-397 \mathrm{COF}+$ $0.3257 \mathrm{DA} \times \mathrm{DA}+2.639 \mathrm{RS} \times \mathrm{RS}+1662 \mathrm{COF} \times \mathrm{COF}-$ $0.090 \mathrm{DA} \times \mathrm{RS}+15.2 \mathrm{DA} \times \mathrm{COF}+44.7 \mathrm{RS} \times \mathrm{COF}$

The diagnostic checking of the model has been carried out by the examination of the residuals. Figure 6 shows the residual analysis data for the extrusion force. It is observed that the residuals fall on a straight line implying that the errors are normally distributed. The regression plot shows the goodness of the developed equation to forecast the extrusion force.

\subsection{Effect of process parameters on Damage}

The influence of process parameters (die angle, ram speed and coefficient of friction) on damage factor is depicted in Figure 7. The results are quoted in Table 7. It is observed that, process parameters increases the damage factor increases. This happened because of increase of extrusion force with increase of process parameters (die angle, ram speed and coefficient of friction) and damage increases. From the ANOVA results, it is observed that the contribution of die angle (DA) individually and its product $\left(\mathrm{DA}^{2}\right)$ is high $(60.85 \%$ \& $12.49 \%)$. The other process parameter ram speed (RS) contribution is significant $(7.37 \%)$ and its product $\left(\mathrm{RS}^{2}\right)$ is less significant $(0.23 \%)$ whereas coefficient of friction (COF) contribution individually and its product is insignificant. In the other interaction parameters the contribution of $\mathrm{DA} \times \mathrm{RS} \quad(10.40 \%)$ is significant and $\mathrm{DA} \times \mathrm{COF}$ $(0.111 \%)$ parameter contribution is less significant. the same can be observed in Table 7 .

Figure $8(\mathrm{a}, \mathrm{b}$ and $\mathrm{c})$ depicts the contour plots of extrusion damage factor by keeping the one parameter as constant and the other two parameters varying. It clearly observed from Figure 8 by increasing die angle with one of the other parameters the damage factor increases and it is considerable after the $20^{\circ} \mathrm{DA}$. Whereas, the ram speed and coefficient of friction influence on damage factor is insignificant. From the ANOVA the optimized process parameters for minimum damage factor is $10^{\circ}$ die angle, $1.6 \mathrm{~mm} / \mathrm{min}$ ram speed and 0.06 coefficient of friction.

The relationship between extrusion process parameters on damage factor is modelled by a polynomial equation with the second order. The regression equations are obtained together with determination coefficients ( $\mathrm{R}^{2}$ adjacent- $87.03 \%$ and $\mathrm{R}^{2}$ predicted $-78.18 \%$ ). The damage factor model is given by equation (7). The proposed model predicts up to the accuracy of $91.5 \%$.

Damage $(\%)=1.18-0.2546 \mathrm{DA}-0.165 \mathrm{RS}-21.4 \mathrm{COF}+$ $0.00679 \mathrm{DA} \times \mathrm{DA}+0.0357 \mathrm{RS} \times \mathrm{RS}+112 \mathrm{COF} \times \mathrm{COF}+$

$0.027397 \mathrm{DA} \times \mathrm{RS}+0.227 \mathrm{DA} \times \mathrm{COF}+0.42 \mathrm{RS} \times \mathrm{COF}$

The diagnostic checking of the model has been carried out by the examination of the residuals. Figure 9 shows the residual analysis data for the damage factor. Form that, it is observed that the residuals fall on a straight line implying that the errors are normally distributed. The regression plot shows the goodness of the developed equation to forecast the damage factor.

\subsection{Effect of process parameters on Extrusion} Force and Damage by using Gray relation analysis The above section explains the influence of process parameters on extrusion force and damage factor individually. The Taguchi method is used to find the optimum parameters. In the present section, the influence of process parameters on extrusion force and damage factor analysed by using grey relation analysis. A direct standardization of the simulation results is used. The optimum output parameters are minimum extrusion force and damage factor. Every response measured since the simulation is regulated in the sort of 0 to 1 which is known as Grey relational generation. Table 8 indicates grey relational coefficients as well as grey relational grades of every simulation estimated by using equation 5 . Among the 27 simulations, simulation 3 results have the maximum grey relation grade.

Figure 10 depicts the influence of considered parameters on GRG and the data from the GRG analysis is as shown in Table 9. Figure 11(a, b and c) depicts the influence of process parameters (die angle, ram speed and coefficient of friction) on GRG. From the individual analysis it is noticed that die angle and ram speed has major influence on extrusion force and damage. Whereas coefficient of friction has insignificant influence on extrusion force and minor influence on damage. So it is expected the die angle and ram speed has significant influence, the same depicts in the contour of DA \& RS. For the other contours it shows the influence in the orientation of coefficient of friction is invariant. From the contour plot of DA \& RS it is observed that the region between the low DA $\left(10^{\circ}-15^{\circ}\right)$, low RS $(1.6$ $\mathrm{mm} / \mathrm{min}$ ) has high GRG. Similarly GRG is high in the bounded region between the low DA \& low COF (DA \& COF) and low \& high COF \& low RS (COF \& RS). The optimum values for the minimum extrusion force and damage factor (i.e. high GRG) are $10^{\circ} \mathrm{DA}, 1.6 \mathrm{~mm} / \mathrm{min} \mathrm{RS}$ and $0.01 \mathrm{COF}$. 
A polynomial equation with the second order is modelled to estimate the GRG values. The regression equations are obtained together with determination coefficients ( $\mathrm{R}^{2}$ adjacent- $74.42 \%$ and $\mathrm{R}^{2}$ predicted $58.45 \%$ ). The proposed model predicts up to the accuracy of $83.27 \%$. The model predicts moderate accuracy is due to the unaccounted the other parameters in extrusion process.

$\mathrm{GRG}(\%)=1.767-0.0292 \mathrm{DA}-0.161 \mathrm{RS}-10.2 \mathrm{COF}+$ $0.000102 \mathrm{DA} \times \mathrm{DA}+0.0113 \mathrm{RS} \times \mathrm{RS}+70.1 \mathrm{COF} \times \mathrm{COF}+$

$0.00518 \mathrm{DA} \times \mathrm{RS}+0.010 \mathrm{DA} \times \mathrm{COF}+0.707 \mathrm{RS} \times \mathrm{COF}$

Table 6. Analysis of Variance for extrusion Force

\begin{tabular}{|c|c|c|c|c|c|c|c|}
\hline Source & DF & Adj SS & Adj MS & F-Value & P-Value & \% of cont & Remarks \\
\hline Model & 9 & 127201 & 14133 & 170.21 & 0.000 & 98.90 & Significant \\
\hline DA & 1 & 111188 & 111188 & 1339.04 & 0.000 & 86.45 & Significant \\
\hline RS & 1 & 8946 & 8946 & 102.31 & 0.001 & 6.96 & Significant \\
\hline COF & 1 & 718 & 718 & 8.65 & 0.009 & 0.56 & Significant \\
\hline DA $^{2}$ & 1 & 6366 & 6366 & 76.67 & 0.000 & 4.95 & Significant \\
\hline RS $^{2}$ & 1 & 271 & 271 & 3.26 & 0.089 & 0.21 & Insignificant \\
\hline $\mathrm{COF}^{2}$ & 1 & 3 & 3 & 0.03 & 0.860 & 0.01 & Insignificant \\
\hline $\mathrm{DA} \times \mathrm{RS}$ & 1 & 25 & 25 & 0.3 & 0.593 & 0.02 & Insignificant \\
\hline $\mathrm{DA} \times \mathrm{COF}$ & 1 & 111 & 111 & 1.33 & 0.264 & 0.09 & Insignificant \\
\hline $\mathrm{RS} \times \mathrm{COF}$ & 1 & 25 & 25 & 0.3 & 0.594 & 0.02 & Insignificant \\
\hline Error & 17 & 1412 & & & & & \\
\hline Total & 26 & 128613 & & & & & \\
\hline
\end{tabular}

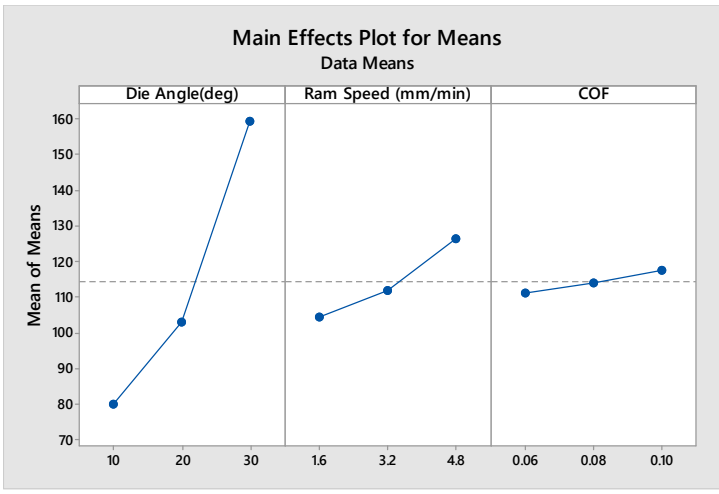

Fig.4. (a) Main effect plots of Extrusion force

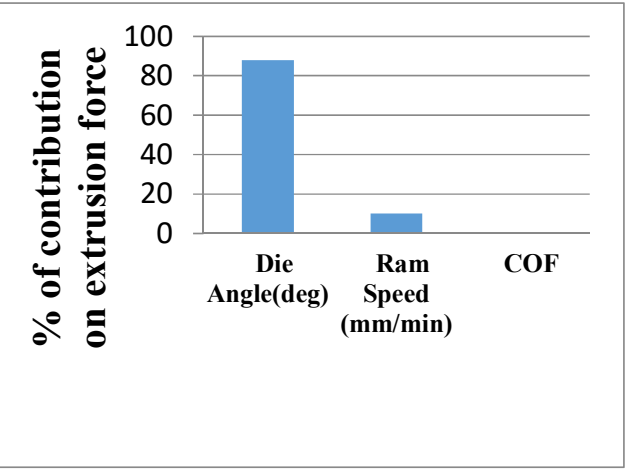

Fig. 4 (b) Percentage contribution of parameters on extrusion force

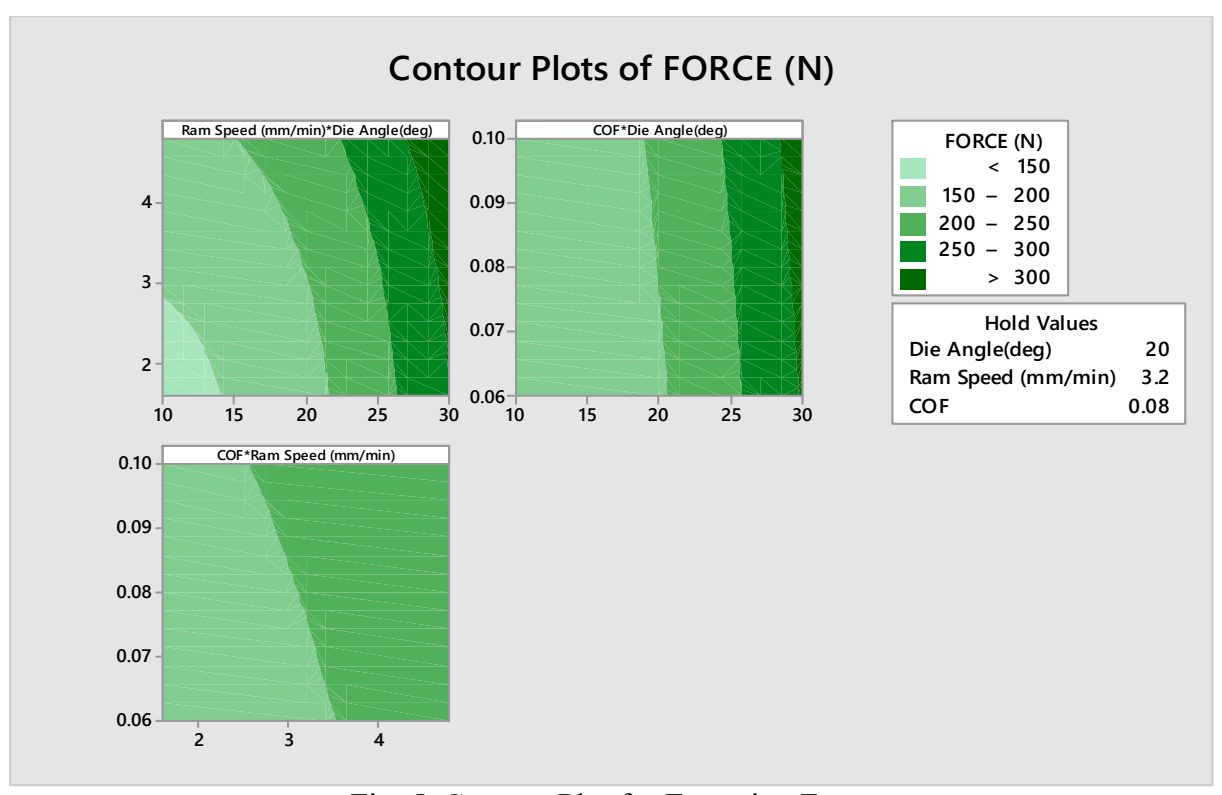

Fig. 5. Contour Plot for Extrusion Force 


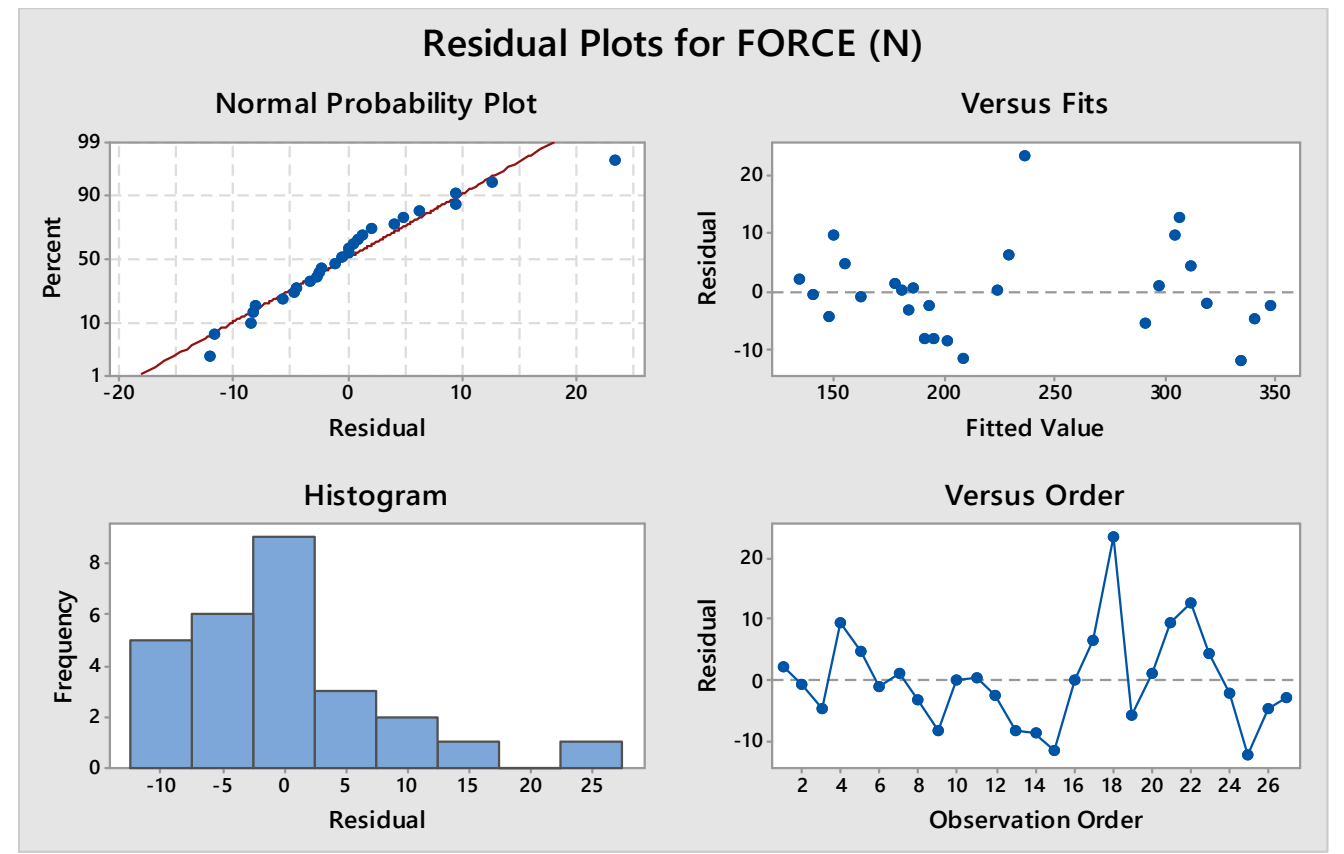

Fig. 6. Residual plots for extrusion force
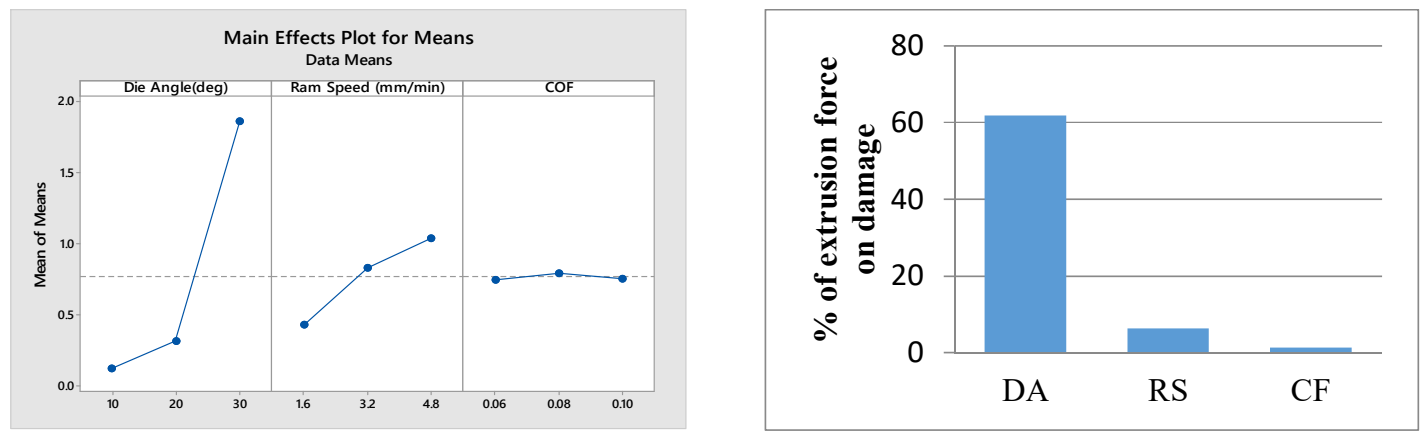

Fig. 7. Main effect plots of Damage and percentage contribution of parameters on extrusion damage

Table 7. Analysis of Variance for Damage

\begin{tabular}{|l|r|r|r|r|r|r|l|}
\hline \multicolumn{1}{|c|}{ Source } & DF & \multicolumn{1}{c|}{ Adj SS } & \multicolumn{1}{c|}{ Adj MS } & \multicolumn{1}{c|}{ F-Value } & \multicolumn{1}{c|}{ P-Value } & \multicolumn{1}{c|}{ \% of cont. } & Remarks \\
\hline Model & 9 & 20.2761 & 2.2529 & 20.39 & 0.000 & 91.52 & Significant \\
\hline DA & 1 & 13.4802 & 13.4802 & 122 & 0.000 & 60.85 & Significant \\
\hline RS & 1 & 1.635 & 1.635 & 14.8 & 0.001 & 7.38 & Significant \\
\hline COF & 1 & 0.0005 & 0.0005 & 0 & 0.946 & 0.01 & Insignificant \\
\hline $\mathrm{DA}^{2}$ & 1 & 2.7667 & 2.7667 & 25.04 & 0.000 & 12.49 & Significant \\
\hline $\mathrm{RS}^{2}$ & 1 & 0.05 & 0.05 & 0.45 & 0.51 & 0.23 & Insignificant \\
\hline $\mathrm{COF}^{2}$ & 1 & 0.0121 & 0.0121 & 0.11 & 0.745 & 0.05 & Insignificant \\
\hline $\mathrm{DA} \times \mathrm{RS}$ & 1 & 2.3048 & 2.3048 & 20.86 & 0.000 & 10.40 & Significant \\
\hline $\mathrm{DA} \times \mathrm{COF}$ & 1 & 0.0247 & 0.0247 & 0.22 & 0.643 & 0.11 & Insignificant \\
\hline RS $\times \mathrm{COF}$ & 1 & 0.0022 & 0.0022 & 0.02 & 0.89 & 0.01 & Insignificant \\
\hline Error & 17 & 1.8783 & 0.1105 & & & & \\
\hline Total & 26 & 22.1545 & & & & & \\
\hline
\end{tabular}


Contour Plots of Damage(\%)
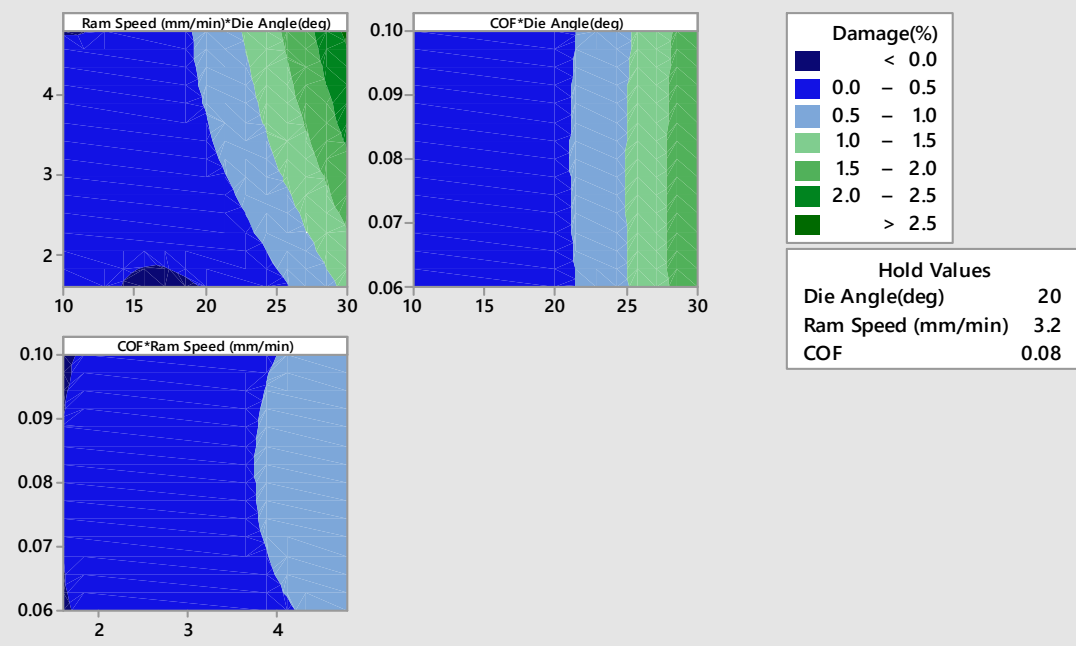

Fig. 8. Contour plots for extrusion damage factor

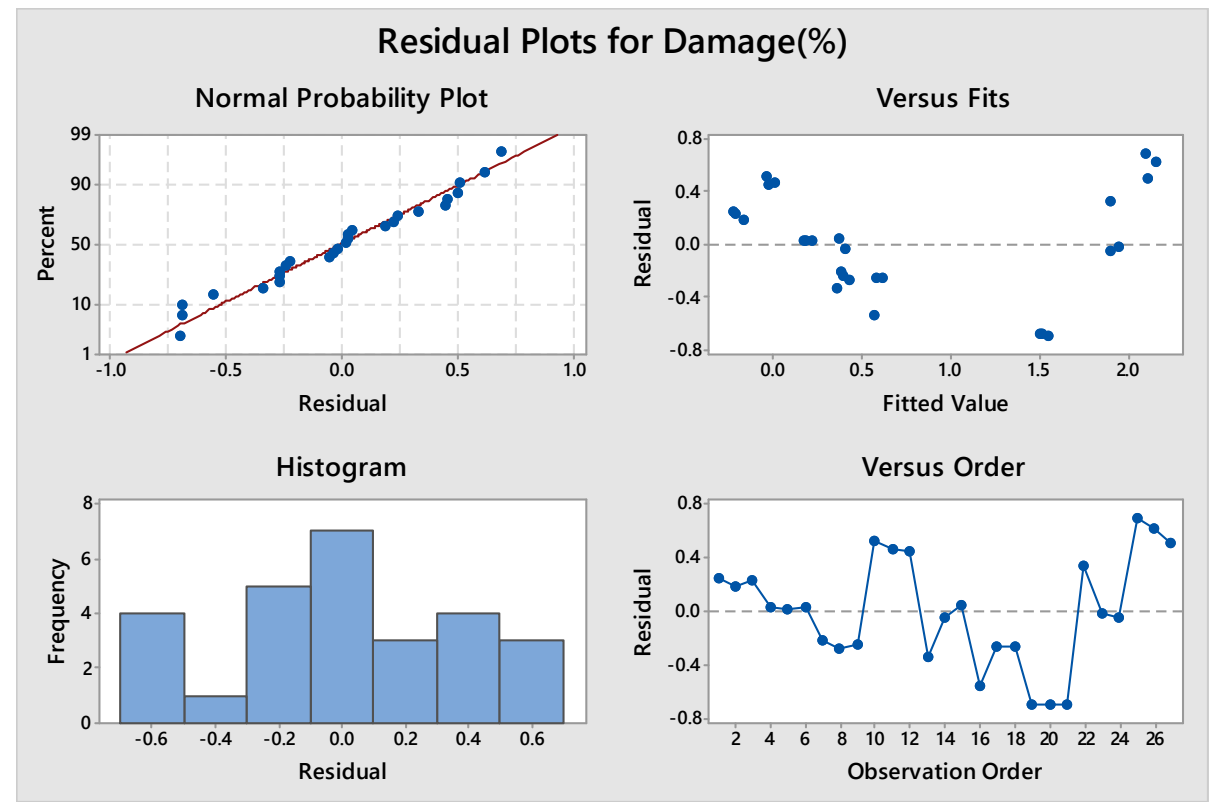

Fig. 9. Residual plots for the damage factor
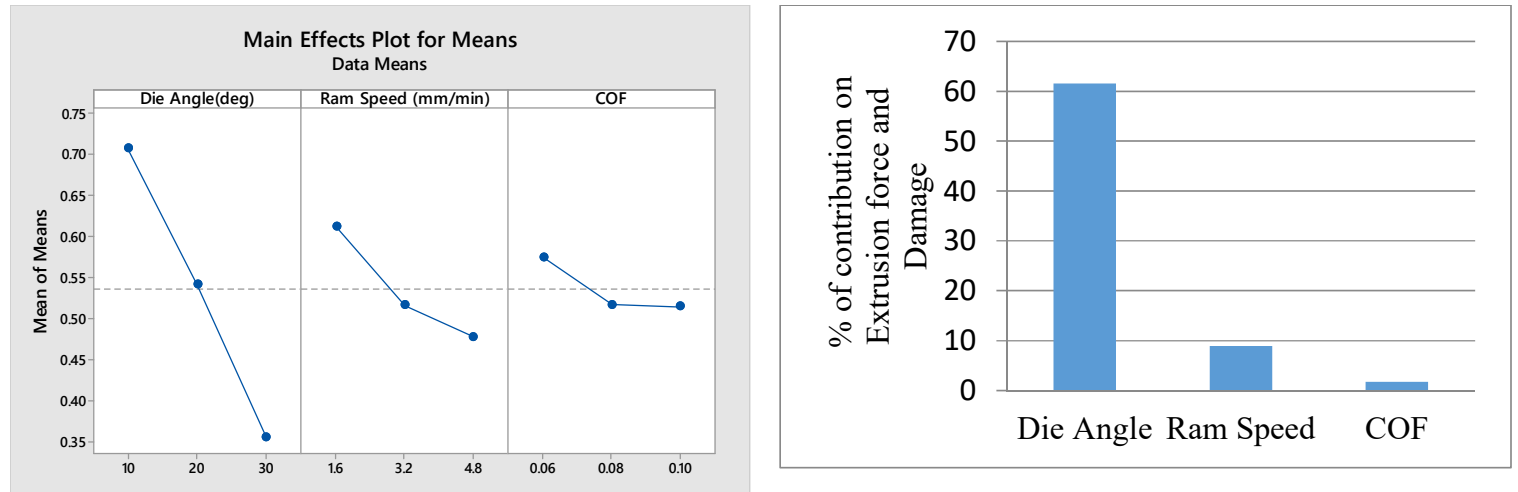

Fig. 10. Main effect plots of GRG and percentage contribution of parameters on extrusion force and damage 
Table 8. Normalized S/N ratio, Grey Relation Grade and Rank

\begin{tabular}{|c|c|c|c|c|c|c|c|c|}
\hline \multirow{2}{*}{$\begin{array}{c}\text { Exp. } \\
\text { No }\end{array}$} & \multicolumn{2}{|c|}{ S/N-Ratio } & \multicolumn{2}{|c|}{ Normalized-S/N-Ratio } & \multicolumn{2}{|c|}{ GRC } & \multirow[b]{2}{*}{ GRG } & \multirow[b]{2}{*}{ Rank } \\
\hline & $\begin{array}{c}\text { Force } \\
(\mathbf{K N})\end{array}$ & $\begin{array}{c}\text { Damage } \\
(\%)\end{array}$ & $\begin{array}{l}\text { Force } \\
(\mathrm{KN})\end{array}$ & $\begin{array}{c}\text { Damage } \\
(\%)\end{array}$ & $\begin{array}{c}\text { Damage } \\
(\%)\end{array}$ & $\begin{array}{c}\text { Force } \\
(\mathbf{K N})\end{array}$ & & \\
\hline 1 & 42.7065 & -35.3910 & 1 & 0.92142 & 1 & 0.86418 & 0.93209 & 3 \\
\hline 2 & 42.9014 & -37.0774 & 0.97579 & 0.95646 & 0.95381 & 0.9199 & 0.93686 & 2 \\
\hline 3 & 43.0830 & -39.1721 & 0.95324 & 1 & 0.91447 & 1 & 0.95724 & 1 \\
\hline 4 & 44.0285 & -14.3340 & 0.83581 & 0.48378 & 0.7528 & 0.49202 & 0.62241 & 6 \\
\hline 5 & 44.0829 & -12.3958 & 0.82905 & 0.4435 & 0.74521 & 0.47326 & 0.60924 & 8 \\
\hline 6 & 44.1419 & -13.5556 & 0.82173 & 0.4676 & 0.73717 & 0.48431 & 0.61074 & 7 \\
\hline 7 & 45.0706 & -15.9721 & 0.70638 & 0.51782 & 0.63003 & 0.50907 & 0.56955 & 9 \\
\hline 8 & 45.1209 & -15.8635 & 0.70015 & 0.51557 & 0.62511 & 0.50791 & 0.56651 & 10 \\
\hline 9 & 45.2162 & -16.4205 & 0.68831 & 0.52714 & 0.616 & 0.51395 & 0.56497 & 11 \\
\hline 10 & 45.1387 & -6.4479 & 0.69793 & 0.31988 & 0.62339 & 0.42368 & 0.52354 & 12 \\
\hline 11 & 45.4238 & -6.5212 & 0.66252 & 0.3214 & 0.59703 & 0.42423 & 0.51063 & 13 \\
\hline 12 & 45.6029 & -7.5765 & 0.64028 & 0.34333 & 0.58158 & 0.43228 & 0.50693 & 15 \\
\hline 13 & 45.4605 & -36.4782 & 0.65797 & 0.94401 & 0.5938 & 0.8993 & 0.74655 & 4 \\
\hline 14 & 45.7017 & -8.7067 & 0.62801 & 0.36682 & 0.5734 & 0.44124 & 0.50732 & 14 \\
\hline 15 & 45.8721 & -7.7443 & 0.60685 & 0.34682 & 0.55981 & 0.43358 & 0.4967 & 16 \\
\hline 16 & 47.0088 & -37.0774 & 0.46567 & 0.95646 & 0.48341 & 0.9199 & 0.70165 & 5 \\
\hline 17 & 47.4586 & -9.1186 & 0.40981 & 0.37539 & 0.45864 & 0.4446 & 0.45162 & 17 \\
\hline 18 & 48.2998 & -10.1728 & 0.30534 & 0.39729 & 0.41853 & 0.45343 & 0.43598 & 18 \\
\hline 19 & 49.1276 & -1.7237 & 0.20253 & 0.22169 & 0.38537 & 0.39114 & 0.38825 & 19 \\
\hline 20 & 49.4954 & -1.2899 & 0.15686 & 0.21268 & 0.37226 & 0.3884 & 0.38033 & 20 \\
\hline 21 & 49.9355 & -1.6184 & 0.10219 & 0.21951 & 0.3577 & 0.39047 & 0.37409 & 21 \\
\hline 22 & 50.0883 & 6.9661 & 0.08322 & 0.04109 & 0.35291 & 0.34272 & 0.34782 & 24 \\
\hline 23 & 50.0088 & 5.7111 & 0.09309 & 0.06717 & 0.35539 & 0.34896 & 0.35217 & 23 \\
\hline 24 & 50.0245 & 5.3903 & 0.09115 & 0.07384 & 0.3549 & 0.35059 & 0.35275 & 22 \\
\hline 25 & 50.1843 & 8.9432 & 0.0713 & 0 & 0.34997 & 0.33333 & 0.34165 & 25 \\
\hline 26 & 50.5283 & 8.8809 & 0.02857 & 0.00129 & 0.33981 & 0.33362 & 0.33671 & 26 \\
\hline 27 & 50.7584 & 8.3660 & 0 & 0.01199 & 0.33333 & 0.33602 & 0.33468 & 27 \\
\hline
\end{tabular}

Table 9. Analysis of Variance for GRA

\begin{tabular}{|l|c|l|l|l|l|c|l|}
\hline Source & DF & Adj SS & Adj MS & F-Value & P-Value & \% of cont & Remarks \\
\hline Model & 9 & 0.75139 & 0.08349 & 9.4 & 0.000 & 83.27 & Significant \\
\hline DA & 1 & 0.55516 & 0.55516 & 62.53 & 0.000 & 61.53 & Significant \\
\hline RS & 1 & 0.08089 & 0.08089 & 9.11 & 0.008 & 8.96 & Significant \\
\hline COF & 1 & 0.01617 & 0.01617 & 1.82 & 0.195 & 1.79 & Insignificant \\
\hline $\mathrm{DA}^{2}$ & 1 & 0.00063 & 0.00063 & 0.07 & 0.794 & 0.07 & Insignificant \\
\hline $\mathrm{RS}^{2}$ & 1 & 0.00504 & 0.00504 & 0.57 & 0.461 & 0.56 & Insignificant \\
\hline $\mathrm{COF}^{2}$ & 1 & 0.00472 & 0.00472 & 0.53 & 0.476 & 0.52 & Insignificant \\
\hline $\mathrm{DA} \times \mathrm{RS}$ & 1 & 0.08259 & 0.08259 & 9.3 & 0.007 & 9.15 & Insignificant \\
\hline $\mathrm{DA} \times \mathrm{COF}$ & 1 & $5.3 \mathrm{E}-05$ & $5.3 \mathrm{E}-05$ & 0.01 & 0.94 & 0.01 & Insignificant \\
\hline $\mathrm{RS} \times \mathrm{COF}$ & 1 & 0.00615 & 0.00615 & 0.69 & 0.471 & 0.68 & Insignificant \\
\hline Error & 17 & 0.15092 & 0.00888 & & & & \\
\hline Total & 26 & 0.90231 & & & & & \\
\hline
\end{tabular}




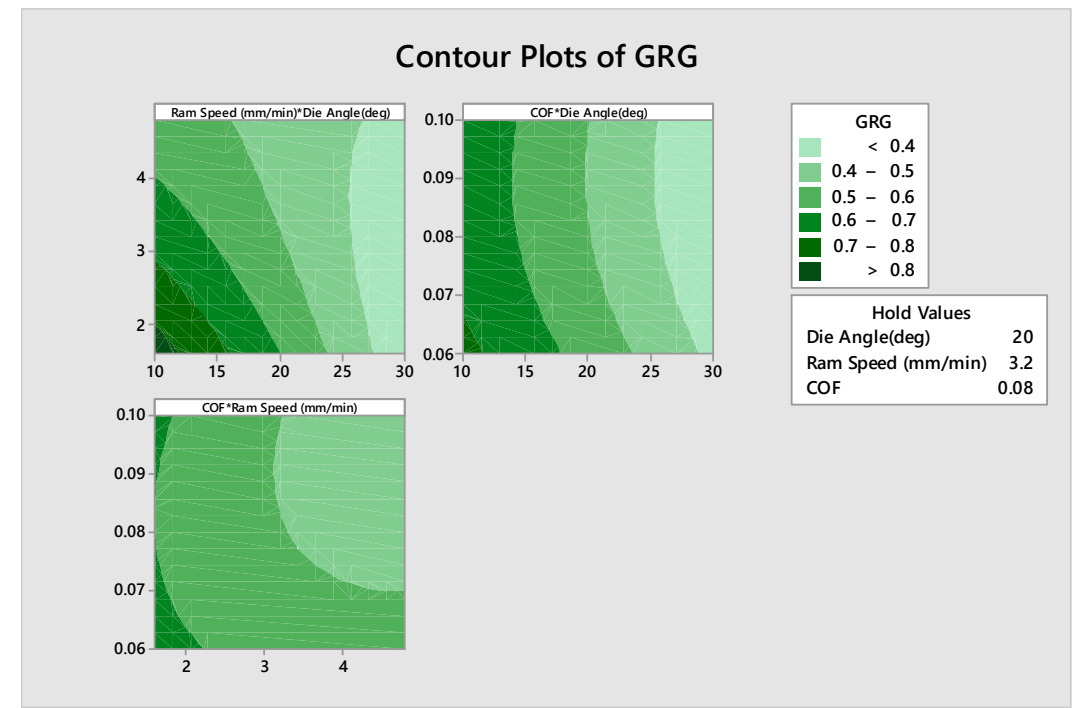

Fig. 11. Contour plots for GRG

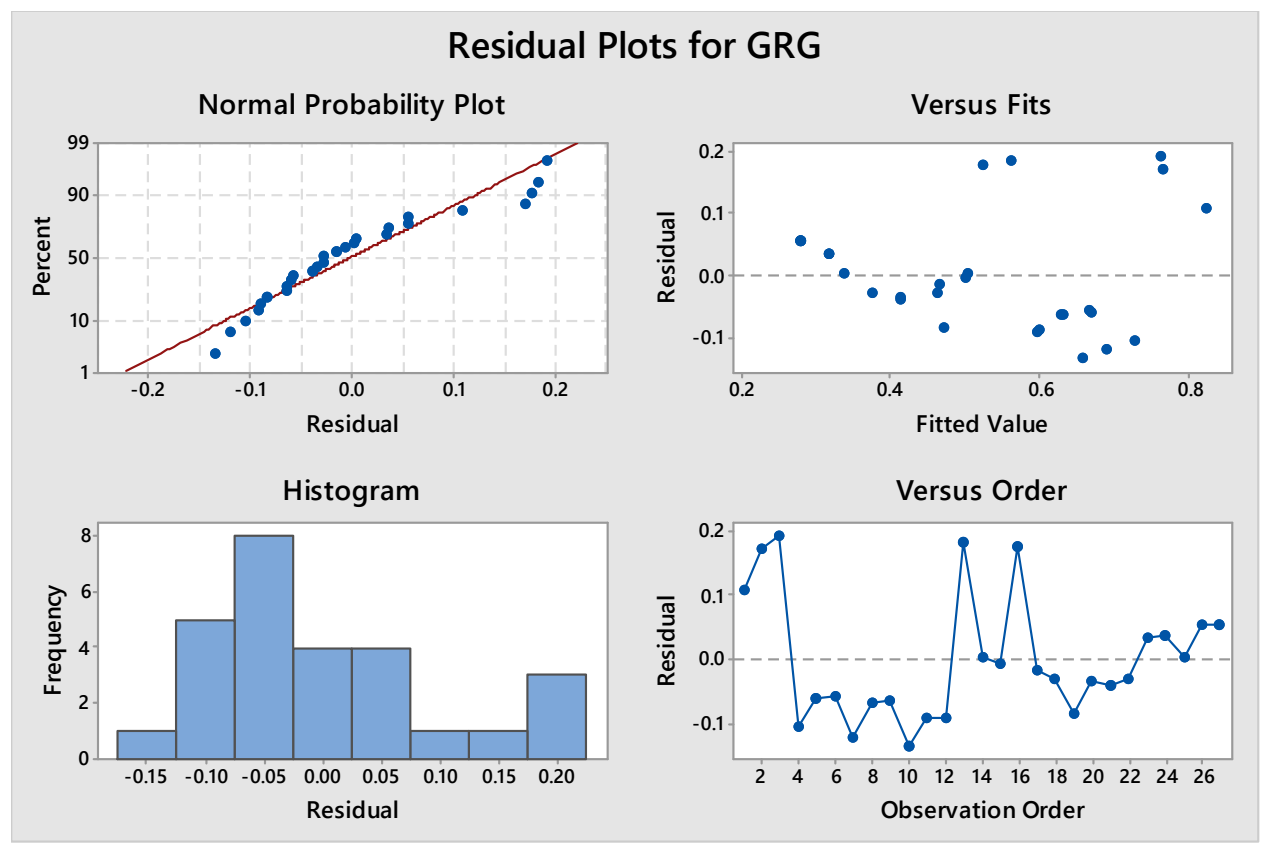

Fig.12. Residual plots for the GRG

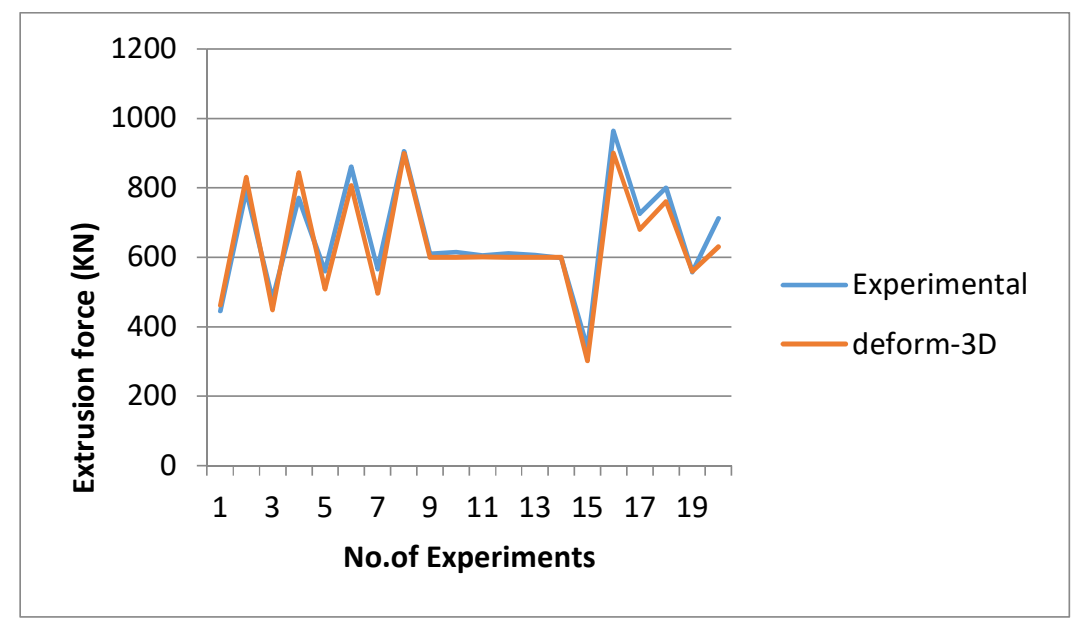

Fig. 13. Variation of experimental data and the simulation data 


\subsection{Validation}

The simulation model used in the present study is validated with the experimental data of the $\mathrm{Z}$ Jurkovic et al. [15]. Experiments are conducted by varying the DA, coefficient of friction and logarithmic strain. Figure 13 depicts the variation of experimental data and the simulation data in terms of extrusion force. It clearly observed that present used simulation model/procedure closely predicts the extrusion force. The average deviation observed is less than $5 \%$.

\section{CONCLUSIONS}

In the present study, the influence of process parameters (Die Angle, Ram Speed and Coefficient of Friction) on cold extrusion process is numerically analysed. The extrusion process is performed for the AA 2024 material and the extrusion force and damage factor are considered as responses. Initially, the process parameters influence is studied individually. Then after multi objective optimization is done by using Taguchi Grey relation analysis. The ANOVA model proposed here describes the contribution of extrusion process parameters on the output responses. The main conclusions of the current study are as follows:

-The extrusion force and damage increases with the increase of process parameters.

-From the Individual ANOVA analysis, it is observed that the DA \& RS has significant influence on extrusion force and damage. Whereas COF influence on extrusion force is insignificant but on the damage is significant.

-Grey relation analysis done for the multi optimization of extrusion force and damage factor. The optimum process parameters obtained for GRG are $10^{\circ}$ die angle, $1.6 \mathrm{~mm} / \mathrm{min}$ ram speed and 0.06 COF. COF influence on extrusion force and damage is significant.

\section{REFERENCES}

1. Karayel D.(2008).Simulation of Direct Extrusion Process and Optimal Design of Technological Parameters Using FEM and Artificial Neural Network. Key Eng Mater.; 367, pp.185-192.

2. Chaudhari GA, Andhale SR, Patil NG (2012). Experimental Evaluation of Effect of Die Angle on Hardness and Surface Finish of Cold Forward Extrusion of Aluminum. Int $\mathbf{J}$ Emerg Technol Adv Eng., 2(7), pp 2-6.

3. Onuh SO, Ekoja M, Adeyemi MB. (2003).Effects of die geometry and extrusion speed on the cold extrusion of aluminium and lead alloys. J Mater Process Technol., 132(1-3), pp. 274-285.

4. Rath D, Tripathy S. (2010), Investigation of
Extrusion of Lead experimentally from Round section through Equilateral Triangular section Converging dies at different area reductions during Forward Metal Extrusion Process. 2013, 3(1), 32-38.

5. Adeosun SO, Sekunow OI, Gbenebor OP( 2014). Effect of Die Entry Angle on Extrusion Responses of Aluminum 6063 Alloy, 4(2), 127-134.

6. Gusel L, Rudolf R. (2008) Different techniques for strain analisys in metal forming processes. Proc Int Conf DAAAM Balt.

7. Murtaza Ali S, Professor A (2013). To Study the Influence of Frictional Conditions and Die Land Length on Component Error and Die Deflection in Cold Extrusion by Finite Element Analysis. J Metall Eng. 2(1), pp.29-38.

8. Yu Y-W, Liu T-J. (1998). A Simple Numerical Approach for the optimal Design of an Extrusion die. Jiurnal Polym Reseach.; 5(1), 1-7.

9. Li F, Lin JF, Yuan SJ, Liu XJ. (2009). Effect of inner cone punch on metal flow in extrusion process. Int J Adv Manuf Technol., 42(5-6), pp.489-496.

10. Lela B, Musa A, Zovko O. (2014). Model-based controlling of extrusion process. Int $\mathrm{J} \mathrm{Adv}$ Manuf Technol., 74(9-12), pp.1267-1273.

11. Oh SI, Wu WT, Tang JP.(1992), Simulations of cold forging processes by the DEFORM system. J Mater Process Tech., 35(3-4), pp.357-370.

12. Sadollah A, Bahreininejad A. (2012). Optimization of die design using metaheuristic methods in cold forward extrusion process. Neural Comput Appl.; 21(8), pp.2071-2076.

13. Chanda T, Zhou J, Duszczyk J. (2001). A comparative study on iso-speed extrusion and isothermal extrusion of 6061 Al alloy using 3D FEM simulation. J Mater Process Technol.; 114(2), pp.145-153.

14. Chanda T, Zhou J, Duszczyk J.( 2000). FEM analysis of aluminium extrusion through square and round dies. Mater Des.; 21(4), pp. 323-335.

15. Jurković Z, Brezočnik M, Grizelj B, Mandic V. (2009) . Optimization of extrusion process by genetic algorithms and conventional techniques. Teh Vjesn., 16(4), pp. 27-33.

16. H. L1. D. (1964). Pugh. Redundant work and friction in the hydrostatic extrusion of pure aluminium and an aluminium alloy, 4, 362-370.

17. Venketesan R. Extrusion Die profile Design using Simulated Annealing and Particle Swarm Optimization. Int J Eng Sci Technol., 2(8), pp.37583761.

18. Venkatesan R, Narayanasamy R, Nadu T (2003). Application of genetic algorithm and simulated annealing for optimization of extrusion die ratio and die cone angle ( Deocoded value). In: Production Engineering. Gliwice-Cracow-Zakopane, Poland: Gliwice : Silesian University of Technology, Institute 
of Engineering Materials and Biomaterials;. 10011006.

19. Rao TB, Krishna AG. (2012). Design and Optimization Of Extrusion Process Using FEA And Taguchi Method. Int J Eng Res Technol., 1(8), 1-5.

20. Farhoumand A, Ebrahimi R. (2009). Analysis of forward-backward-radial extrusion process. Mater Des [Internet]. 2009, 30(6), 2152-2157. Available from: http://dx.doi.org/10.1016/j.matdes.2008.08.025 21. Silva MB, Carneiro LM, Paulo J, Silva A, Oliveira S, José H, et al (2014). An Application of the Taguchi Method ( Robust Design) to Environmental Engineering: Evaluating Advanced Oxidative Processes in Polyester-Resin Wastewater Treatment. Ameican J o Analyical Chem., 5, pp. 828-837.

22. Singh S, Singh I, Dvivedi A (2013). Multi objective optimization in drilling of Al6063 / $10 \%$ $\mathrm{SiC}$ metal matrix composite based on grey relational analysis. J Eng Manuf., 227(12), pp. 1767-1776.

23. T. Sheppard, Extrusion of AA 2024 alloy (1993), Materials Science and Technology, 9, 430-440.

24. Z. Liu, P.H. Chong, A.N. Butt, P. Skeldon, G.E. Thompson, (2005), Corrosion mechanism of lasermelted AA 2014 and AA 2024 alloys Applied Surface Science 247, 294-299.

25. Sarojini Jajimoggalaa, Routhu Dhananjay, VVK Lakshmi, Shabana, (2019), Multi-response optimization of hot extrusion process parameters using FEM and Grey relation based Taguchi method. Materials Today: Proceedings, 18, 389-401.
Received: July 25, 2021 / Accepted: December 15, 2021 / Paper available online: December 20, 2021 (C) International Journal of Modern Manufacturing Technologies 